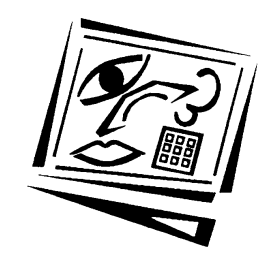

\title{
A context-aware ubiquitous learning approach to conducting scientific inquiry activities in a science park
}

\author{
Gwo-Jen Hwang, Chin-Chung Tsai \\ National Taiwan University of Science and Technology \\ Hui-Chun Chu \\ Soochow University \\ Kinshuk \\ Athabasca University \\ Chieh-Yuan Chen \\ National University of Tainan
}

\begin{abstract}
Fostering students' scientific inquiry competence has been recognised as being an important and challenging objective of science education. To strengthen the understanding of science theories or notations, researchers have suggested conducting some learning activities in the field via operating relevant devices. In a traditional infield scientific inquiry activity, the teacher usually lets the students operate the devices on their own after demonstrating the operational procedure. With such an approach, the students are likely to suspend the practice when they encounter problems; moreover, it is difficult for the students to connect what they have learned from the textbooks with the field practice. To deal with this problem, this study presents a context-aware ubiquitous learning system with sensing technology to detect and examine the real-world learning behaviours of students, such that personalised learning guidance and feedback can be provided; moreover, the students' experiences of operating those scientific devices, such as solar power equipment or the constellation simulators, can be conjunct to the knowledge learned from the textbooks. The experimental results from a science course of an elementary school show that this innovative approach is able to improve the learning achievements of students as well as enhance their learning motivation.
\end{abstract}

\section{Introduction}

Among the wide range of educational objectives, fostering the scientific inquiry competence of students has been recognised as being an important and challenging aim (National Research Council, 2000). Scientific inquiry refers to the ways in which scientists study the natural world and propose explanations based on the derived evidence or observed outcomes (Chen, 2010; Gerber, Ketelhut \& Schifter, 2011). Educators have indicated that most students have difficulty proposing a hypothesis based on what they have observed in the field and finding the answers by determining a problem-solving procedure; moreover, they have difficulty linking the field observation with the knowledge learned from their textbooks (Anderson, Lucas, Ginns \& Dierking, 2000; Leng et al., 2009). Researchers have pointed out the importance of allowing students to have opportunities to observe scientific phenomena and build their own sense of reality during the science learning process (Tomkins \& Tunnicliffe, 
2001). Therefore, the experiences of operating scientific devices in predicting, observing and explaining scientific phenomena is an important part of science education (Dalgarno, et al., 2009).

Previous studies of science learning have shown that observing scientific phenomena and operating scientific devices allows students to link the scientific theories learned from the textbooks with those authentic phenomena (Atkins, Velez, Goudy \& Dunbar, 2009; Phillips, Finkelstein \& Wever-Frerichs, 2007). Such in-field practical experiences have been recognised as being helpful to the students in deepening their conceptions and developing procedural knowledge of science topics in an effective way (Kong, Yuen \& Wu, 2009). Researchers have, however, indicated several problems of conducting such practical field activities, including the lack of personalised learning guidance and of in-time feedback (Hwang, Shi \& Chu, 2011; Tseng \& Tsai, 2007). In the traditional one-to-many instructional mode, students might fail to keep up with the infield instructions given by the teachers, and might need to spend a long time waiting for feedback from the teachers; that is, they might not have enough time to fully experience and understand the scientific inquiry process. Consequently, it is important to situate students in a learning environment that provides learning guidance and timely feedback for individual students.

Recently, advances in wireless communication, sensing and mobile technologies have provided new opportunities to carry out new learning strategies by integrating realworld learning environments and the resources of the digital world (Chen, Hwang, Yang, Chen \& Huang, 2009; Hung, Lin \& Hwang, 2010; Sharples, Taylor \& Vavoula, 2007). For example, Rogers et al. (2005) reported on the Ambient Wood project, in which pairs of children explored in the woodland to find out the different habitats of plants and animals and the relationships between them. The participants were equipped with a probe tool to collect information about moisture and light in the habitats. The readings were displayed on a handheld device with a GPS (Global Positioning System) to record the children's position.

Through these new technologies, individual students, by using mobile devices to access digital content via wireless communications, are able to learn in real-world situations with support or instruction from computer systems; moreover, the learning systems are able to detect and record the students' learning behaviours in both the real world and the digital world with the help of the sensing technologies. Such a technology-enhanced learning approach has been called context-aware ubiquitous learning by Hwang, Tsai and Yang (2008). It not only provides learners with an alternative to deal with problems in the real world, but also enables the learning system to interact with the learners more actively (Ogata \& Yano, 2004). Consequently, with these new technologies, it has become possible to offer students instant learning guidance and feedback while they are practising using scientific devices in a fieldbased learning activity (Hwang, Chu, Lin \& Tsai, 2011). More importantly, their experiences of operating those scientific devices can be integrated with the knowledge learned from their textbooks.

In this paper, a context-aware ubiquitous learning system that employs RFID (Radio Frequency Identification) technology for detecting the learning behaviours of students and providing learning guidance to them in a scientific inquiry activity conducted in an authentic environment is presented. Moreover, a learning activity in an existing science course has been conducted to evaluate the effectiveness of the innovative approach in comparison with the traditional approach. 


\section{Relevant research}

Educators have advocated scientific inquiry activities in which students are encouraged to construct scientific understanding through an iterative process of theory building, criticism, and refinement, based on making hypotheses, observations and interpreting the data on their own (Manlove, Lazonder \& de Jong, 2006). The rapid advancement of computer technologies has attracted researchers to develop simulation environments in which learners can interact with virtual apparatus and materials for scientific inquiry activities, including exploring, testing hypotheses, and interpreting data (Chen, 2010; Ketelhut \& Schifter, 2011).

During this process, carried out via operating scientific devices which simulate science phenomena, students might fail to acquire the correct knowledge owing to improper operations (Reeves, 1993); on the other hand, they might give up on the learning tasks when they encounter problems, if proper prompt assistance is not provided. In particular, in the traditional one-to-many instructional mode, the teacher might not be able to provide immediate assistance to individual students, and hence the students need to wait for a long time before their problems can be solved; consequently, they might not have enough time to fully experience the scientific inquiry process. Moreover, for elementary school students, the scientific inquiry activities could be too difficult, implying that the provision of learning supports is necessary.

In the meantime, researchers have emphasised the importance of providing feedback mechanisms to engage students in reflective thinking (Li, Liu \& Steckelberg, 2010). Burleson (2005) has indicated that awareness and reflection are helpful to students in developing their meta-cognition abilities. The studies undertaken by Johnson, Perry and Shamir (2010) and Panjaburee, Hwang, Triampo and Shih (2010) have further shown that the provision of feedback is beneficial for students' learning achievement.

The efficiency and popularity of mobile and sensing technologies have provided a good opportunity to provide guidance and instant feedback for individual students in scientific inquiry activities. Via sensing technologies, the learning system is able to detect the locations of the students; furthermore, via mobile and wireless communication technologies, the learning system can provide hints or guidance for individual students through the mobile device (Hwang, Chu, Lin \& Tsai, 2011). Several studies have suggested the key steps of instructional design for providing learning supports in context-aware u-learning activities (Hwang et al., 2008), including the selection of learning contexts for representing the particular knowledge to be learned (Hwang, Tsai \& Yang, 2008), the provision of hints or guidance for students to operate in the real-world context (Hwang, Yang, Tsai \& Yang, 2009; Williams van Rooij, 2009), and the assignment of learning missions and roles to individual students in the context (Paige \& Daley, 2009). In recent years, several studies have been conducted to demonstrate the practice of providing learning supports using mobile devices (ElBishouty, Ogata \& Yano, 2007; Schiaffino et al., 2008). For example, Hwang, Wu, Tseng and Huang (2011) presented a learning environment to provide learning supports using mobile devices and sensing techniques for the personal computer assembly learning activity of a university computer course. Following the suggestions of these studies, we aim to develop a context-aware u-learning system to provide learning guidance and instant feedback to support individual students in completing their learning missions in a science park which involves operating scientific devices that are highly related to the context of their school textbooks. 
In the following sections, we present a context-aware u-learning system that is able to provide instant learning guidance and feedback for supporting scientific inquiry activities in a science park. In addition, the experimental results from conducting a learning activity on a science course are presented to demonstrate the effectiveness of this novel approach.

\section{Location-aware ubiquitous learning environment for scientific inquiries}

In this study, the learning environment is a science park located in southern Taiwan. It contains various scientific devices, of which nine concerning planetology, optics and electromagnetic induction were selected as the target learning objects for this study. These devices are related to the content of the elementary school natural science courses; however, even with the instructions and demonstrations provided by the teachers, students still have difficulty understanding the usage of these devices, not to mention linking the outcomes of using these devices with what they have learned from their textbooks. In the developed context-aware ubiquitous learning environment, especially designed to overcome these problems, each target device is labeled with an RFID tag, while each student holds a mobile device equipped with an RFID reader. In addition, wireless communication is provided to enable communication between the mobile device and the computer server that executes the learning system.

The students who participate in the learning activity are guided to learn to operate the specified devices in the science park. As they move around in the authentic learning environment, the learning system can detect the location of the individual students by reading and analysing the data from the nearest RFID tag. Accordingly, the learning system is able to actively provide personalised guidance or hints to individual students by interacting with them via the mobile device, as shown in Figure 1.

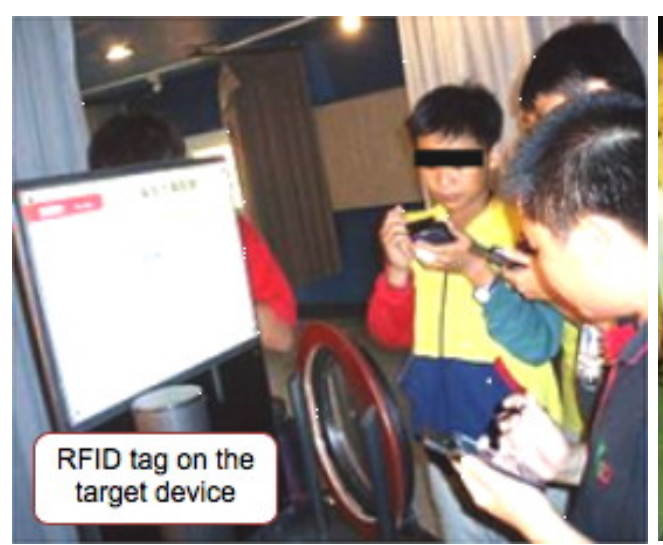

(a)

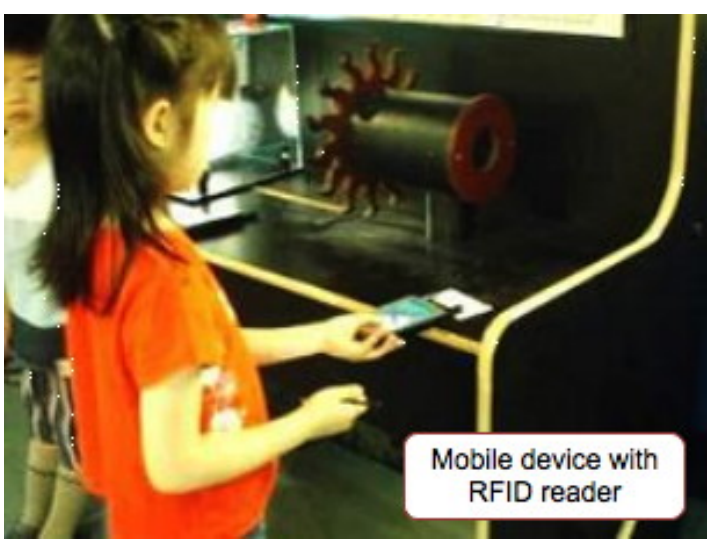

(b)

Figure 1: The ubiquitous learning environment and learning scenario

\section{Ubiquitous learning guidance mechanism for scientific inquiries}

A personalised learning guidance mechanism was employed in developing the ubiquitous learning system for assisting the students to learn to operate those target devices, by employing a cognitive apprenticeship approach; that is, the system was designed to instruct and demonstrate the usage and operation processes of individual 
devices in the field, and the students learned to operate the devices and link the operations and outcomes with the knowledge learned from the textbooks via observing, practising and reflecting, with help from the learning system (Hwang et al., 2009). We aim to provide systematic teaching and personalised guidance for the learners, and opportunities to practise the learning tasks as well as to review the learning processes. The flowchart of the learning guidance mechanism is given in Figure 2.
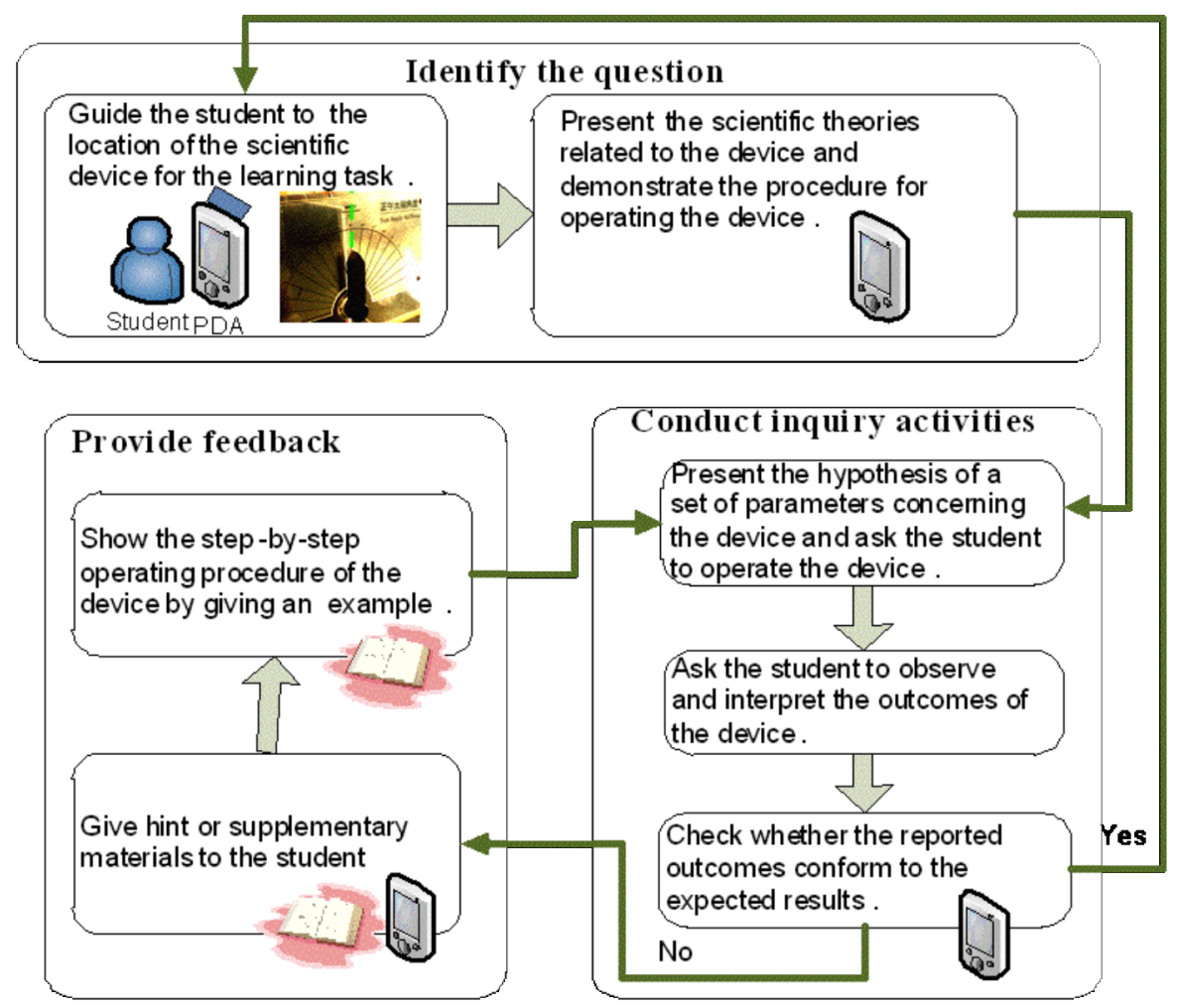

Figure 2: Ubiquitous learning guidance mechanism for scientific inquiries

With the help of the sensing technology, the ubiquitous learning system can detect the location of individual students, and guide them to find the location of the target devices. Once a student arrives at a target device, a series of questions is presented to guide him/her to operate it. Moreover, the learning system guides individual students in further learning based on their responses to the questions; that is, personalised guidance is provided. The details of the personalised ubiquitous learning guidance procedure are given as follows:

\begin{tabular}{|l|l|}
\hline $\begin{array}{l}\text { Step 1: Identify the question to } \\
\text { be investigated. }\end{array}$ & $\begin{array}{l}\text { Step 1.1: Present the theories and examples that are relevant } \\
\text { to the question. }\end{array}$ \\
\cline { 2 - 2 } & Step 1.2: Explain the question to be investigated. \\
\hline $\begin{array}{l}\text { Step 2: Find the target scientific } \\
\text { devices related to the question. }\end{array}$ & $\begin{array}{l}\text { Step 2.1: Confirm that the student is in the location of the } \\
\text { target device. }\end{array}$ \\
\cline { 2 - 2 } & $\begin{array}{l}\text { Step 2.2: Demonstrate the functions of the device and show } \\
\text { how the device can be operated. }\end{array}$ \\
\hline
\end{tabular}




\begin{tabular}{|l|l|}
\hline $\begin{array}{l}\text { Step 3: Conduct the inquiry } \\
\text { activities }\end{array}$ & $\begin{array}{l}\text { Step 3.1: Present the hypothesis of a set of parameters and ask } \\
\text { the student to operate the device in order to find the answer. }\end{array}$ \\
\cline { 2 - 2 } & $\begin{array}{l}\text { Step 3.2: If the student fails to correctly operate the device or } \\
\text { interpret the outcomes (i.e., the results are incorrect), some } \\
\text { hints or supplementary materials are given, and the student is } \\
\text { asked to go back to Step 2. }\end{array}$ \\
\hline & $\begin{array}{l}\text { Step 3.3: If the student correctly operates the device and } \\
\text { interprets the outcomes (i.e., the results are correct), the } \\
\text { learning system will give some encouraging feedback. }\end{array}$ \\
\hline $\begin{array}{l}\text { Step 4: Guide the student to investigate the next question and repeat Steps 1 to 3 until the } \\
\text { student passes the evaluation for all of the target devices. }\end{array}$ \\
\hline
\end{tabular}

\section{Ubiquitous learning system for science device operations}

Based on the proposed approach, the Ubiquitous Scientific Device Trainer (USDT) has been developed to assist the students in operating the scientific devices. USDT is able to detect the location of individual students and provide them with adaptive supports via the use of PDAs (Personal Digital Assistants) equipped with RFID and wireless communication equipment. Figure 3 shows an illustrative example of USDT guiding the students to find the target device "Sun simulator" at the science park for carrying out a learning task.

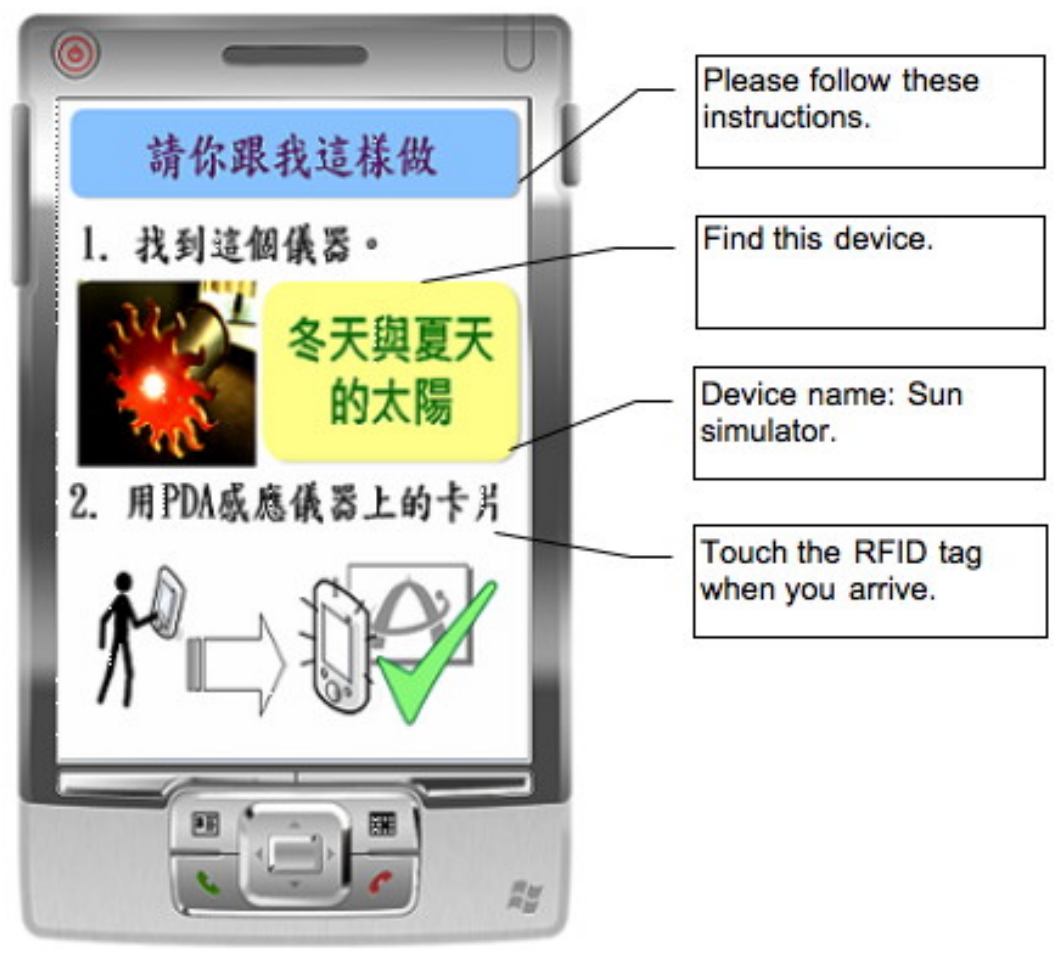

Figure 3: Example of guiding the student to find the target device

When they have arrived at the location of the target device, the students are asked to operate it by following the instructions given by the learning system. In the example given in Figure 4, the theories concerning "Solar thermal power" are introduced, and 
the students are asked to predict what will happen if the angle of the sunshine changes in different seasons. Some possible hypotheses concerning this issue are presented on the PDA, and the students are asked to operate the device and report their findings. For example, in Figure 5, the question is "Assume that the pointer of the device shows the solar power. When the angle of the sunshine becomes smaller, will the heat on the earth decrease or increase?"

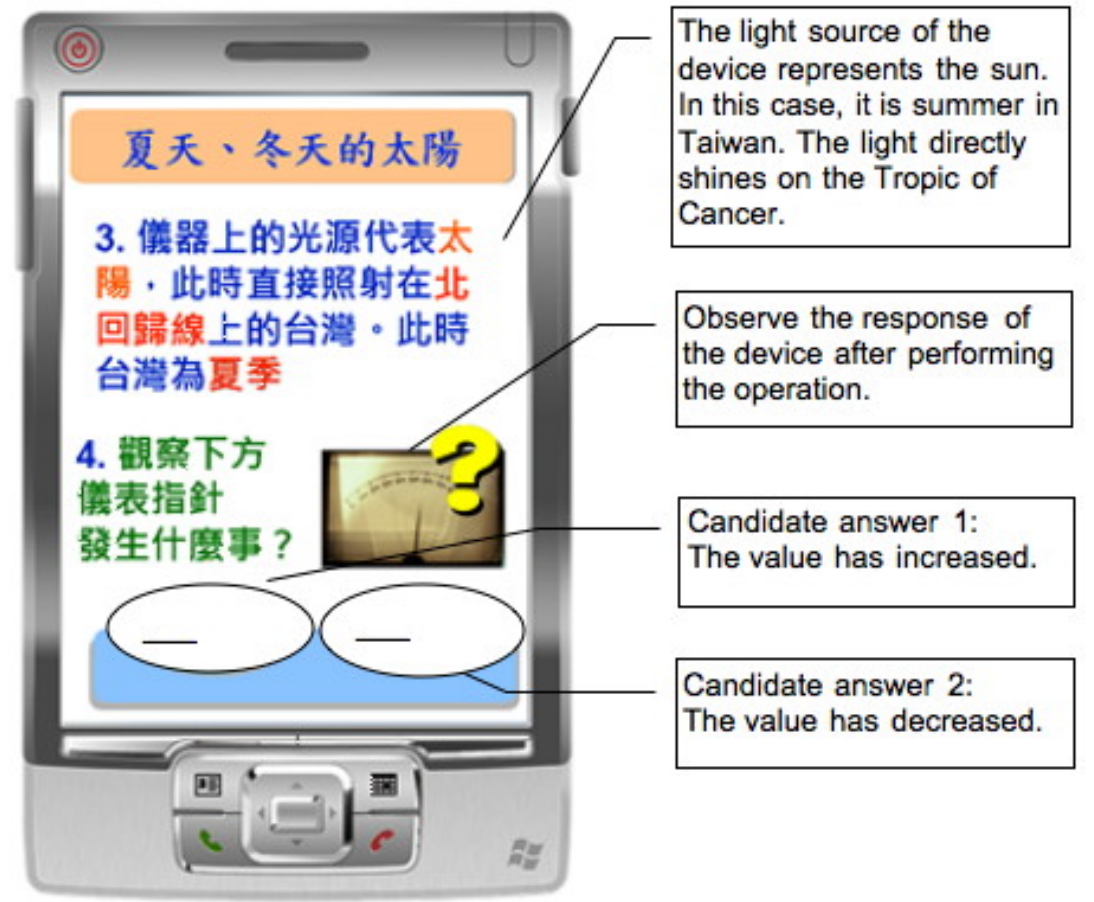

Figure 4: Example of asking the student about the readings of the device panel after performing the operation

If the student fails to correctly answer the question, implying that the operation of the device or the interpretation of the outcome is incorrect, the USDT system will provide hints or supplementary materials which were designed by two teachers who have more than five years experience teaching natural science courses and conducting relevant in-field activities. For example, in Figure 5, the USDT system guides the students to operate the device by turning the red arrow on the device and making it point to the "earth" label (see Figure 5(a)), and then turning the black arrow to the 90degree position (see Figure 5(b)).

\section{Experiment design}

To evaluate the effectiveness of the innovative approach, a quasi-experiment was conducted in a science park located in a small town in southern Taiwan in April, 2009. The learning activity is part of the existing science curriculum of the schools surrounding the science park. Each year, the students of these schools are arranged to visit the science park and to operate the scientific devices to complete the learning tasks designed by the teachers. We aimed to compare the learning outcomes of the 


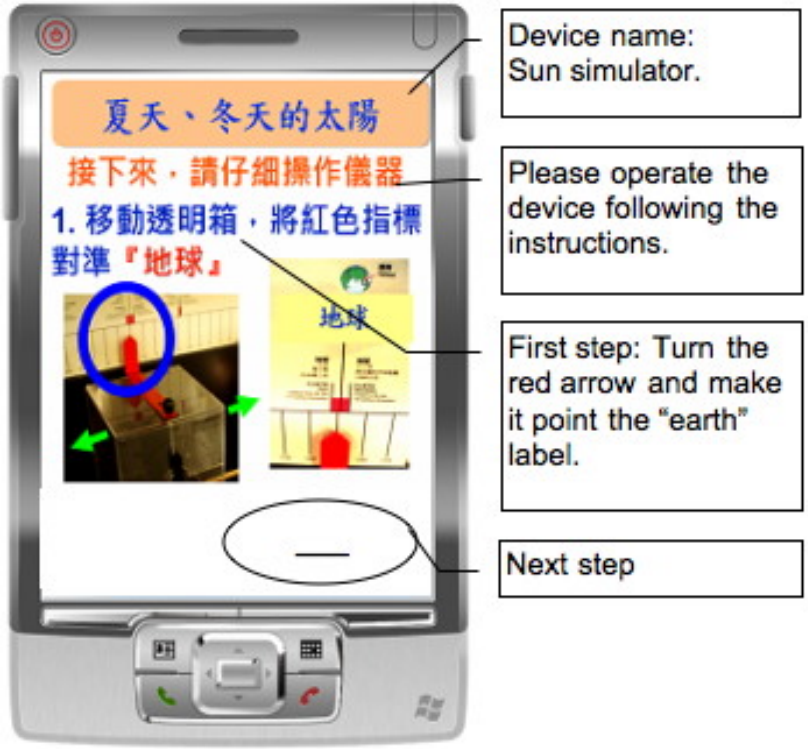

(a)

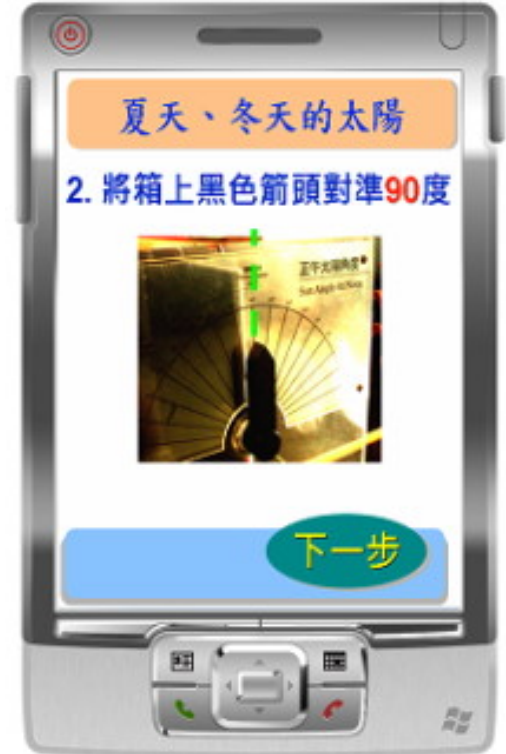

(b)

Figure 5: Example of guiding the student to operate the target device

students who learned with USDT and those who learned with the traditional approach. In the following subsections, the design of the experiment is given in detail.

\section{Participants}

The participants were two classes of fifth grade students from an elementary school in southern Taiwan. The students were on average 11 years old, and were taught by the same teacher. After receiving the fundamental knowledge in a science course, one class of students was assigned to be the control group $(n=21)$ while the other was assigned to be the experimental group $(\mathrm{n}=22)$.

\section{Learning design}

In the first stage of the experiment, the students were given fundamental instruction about the target devices in the science park (about 80 minutes). All of the students were then asked to answer a pre-questionnaire and take a pre-test (50 minutes). The question items in the pre-questionnaire were concerned with the students' attitudes toward the science course. The pre-test aimed to evaluate the students' basic knowledge, including the scientific theories and phenomena related to the selected scientific devices.

In the second stage, the students in the experimental group learnt how to operate the nine target devices using USDT. The control group students learnt with the traditional inquiry-based approach; that is, the teachers instructed and demonstrated the operation of the devices, and then asked the students to operate the devices to complete the inquiry-based tasks on a learning sheet. This stage took almost 120 minutes. After conducting the learning activity, the students were asked to take a post- 
test to evaluate their learning achievements, and answer a post-questionnaire to investigate their perceptions of the ubiquitous learning approach (50 minutes).

\section{Instruments}

The instruments of this study included a pre-test, a post-test, and a questionnaire for investigating several aspects of the students' learning perceptions. All activities and instruments were conducted in Chinese and the translations of quotations were made by the authors.

The pre-test and post-test were designed by two experienced teachers. The pre-test was concerned with "basic scientific knowledge related to the devices in the science park", and consisted of twenty multiple choice questions $(80 \%)$ and one short answer question $(20 \%)$. The post-test, a detailed test about the scientific knowledge and theorems to evaluate the students' ability in applying them to practical problems, was made up of three parts, including twenty multiple-choice questions (40\%), ten fill-inthe-blank questions (30\%) and five short-essay questions (30\%). For example, one of the multiple-choice questions was "John wants to dig a well. He wants the sun to shine on the bottom of the well only on the day of winter solstice. What is the best location for digging the well? (a) the Tropic of Cancer; (b) the equator; (c) the Tropic of Capricorn."

A questionnaire was developed to investigate some aspects of the students' learning perceptions of the system. It was reviewed by three experts to ensure its content validity. After two iterations of reviews and revisions, the questionnaire items demonstrated good reliability with a Cronbach's alpha of .90. It consisted of three aspects based on a six-point Likert-scale: eleven items about the students' "General perceptions of science learning", three items about the "Ease of using the ubiquitous learning system", and six items about the "Helpfulness of the ubiquitous learning activity", with Cronbach's alpha values of $0.83,0.70$ and 0.79 , respectively. These values were obtained from the answers by all of the students who participated in this learning activity. For example, some of the "General perceptions toward science learning" questionnaire items were "I became more willing to observe and investigate those science phenomena after participating in this ubiquitous learning activity"; "I feel that using the PDA to learn is more interesting than the traditional teacher-guided approach"; "I think the PDA-approach enables me to learn more about those scientific devices"; "I would like to learn science courses with the PDA approach again"; and "I will recommend the PDA approach to other teachers and students".

\section{Results}

\section{Learning achievements of the students}

The students' answers to the pre-test and the post-test were evaluated by the two teachers who developed the test items. The scores rated by the two teachers were highly consistent, with Spearman's rho correlation coefficients of $0.996(p<.001)$ and 0.991 ( $p<.001)$ for the pre-test and the post-test, respectively. It was found that the mean and standard deviation of the pre-test were 71.14 and 14.56 for the experimental group, and 73.09 and 11.21 for the control group. As the p-value (significant level) is greater than .05 and $t=-.965$, it can be inferred that the experimental group and the control group did not significantly differ in the pre-test. That is, it was evident that the two groups of students had equivalent abilities before learning the subject unit. 
Table 1 shows the $t$-test results of the post-test. From the post-test scores, it was found that the students in the experimental group had significantly better achievements than those in the control group $(t=2.11, \mathrm{p}<.05)$. This result implies that learning with USDT in an authentic learning environment significantly benefited the students more than learning in the traditional environment. That is, this innovative approach is helpful to the students in improving their learning performance. This result conforms to the finding of Marx et al. (2004) that well-designed inquiry-based activities can achieve statistically significant increases on the curriculum-based test scores of the participants.

Table 1: $t$-test of the post-test results

\begin{tabular}{|l|c|c|c|c|}
\hline & $\mathrm{N}$ & Mean & S.D. & $t$ \\
\hline Experimental group & 22 & 70.55 & 15.42 & $2.11^{*}$ \\
\hline Control group & 21 & 60.19 & 16.76 & \\
\hline${ }^{*} \mathrm{p}<.05$
\end{tabular}

\section{Questionnaire responses}

We collected questionnaire responses from the 22 students in the experimental group after conducting the ubiquitous learning activity. For the "General perceptions of science learning" aspect, it was found that most of the students enjoyed learning the science courses with USDT. For example, 95\% of the students indicated that "I became more willing to observe and investigate those science phenomena after participating in this ubiquitous learning activity" and $100 \%$ of the students admitted that they became more willing to take the science course after participating in the learning activity. In addition, $100 \%$ of the students indicated that using such a PDA learning system is more interesting and enables them to learn more about those scientific devices. All of the students indicated that they would like to learn science courses with this approach in the future, and would recommend it to others.

For the "Ease of using the ubiquitous learning system" aspect, most of the students felt that the PDA system was easy to use. For example, $100 \%$ of the students indicated that "The learning system is easy to use," $86 \%$ of the students indicated that "It took me only a short time to learn to use the PDA system for this learning activity" and 95\% of the students indicated that "The learning materials presented by the PDA are easy to follow."

For the "Helpfulness of the ubiquitous learning activity" aspect, most of the students gave positive feedback to the questionnaire items concerning the learning activity design. For example, $100 \%$ of the students indicated that "I endeavored to follow the learning guidance given by the system during the learning process"; $91 \%$ of the students indicated that "The guidance provided in the learning activity makes me better understand the theoretical basis and the operating procedure of those scientific devices" and $82 \%$ of the students felt that "the learning materials make me understand better what I have learned from the textbook." In addition, 95\% of the students indicated that they became familiar with the operating procedure of each science device after participating in this learning activity.

To sum up, the use of the USDT system to support this in-field scientific inquiry activity was highly acceptable to the students. Most of the students showed their willingness to participate in such learning activities in the future, and would like to 
recommend this learning system to other classmates. Moreover, they would like to apply this innovative approach to other courses to improve their learning performance.

\section{Interviews with the teachers}

In order to have a better understanding of the learning effectiveness of the ubiquitous learning environment for the science course, three teachers (TA, TB and TC) who experienced the ubiquitous learning system took part in independent, semi-structured interviews carried out by one of the authors. All of the three teachers had more than seven years experience of teaching the science course. The interview questions mainly explored the teachers' responses and suggestions after experiencing the ubiquitous learning environment set up in the science park. All of the interviews were recorded by a digital recorder, and all of the relevant data were then transcribed and analysed by the authors.

When asked about the differences between the ubiquitous learning system and the one-to-many instructional process, it was found that the three interviewed teachers shared a consistent point of view, considering "personalisation" and "participation" to be the remarkable benefits of this ubiquitous learning approach.

Taking the "personalisation" aspect for example, TA stated that: "Unlike the one-tomany teacher-led training process, the ubiquitous learning system is much more personalised, because it will clearly remind individual students of every detailed thing and allow them to review those contents as they need to." He favoured such a learning program, stating that, "The learner can go over the operating sequence repeatedly with the ubiquitous learning system instead of asking the same questions of the teacher." TA believed that the ubiquitous learning system could increase the students' learning effectiveness. As another example, when asked about the advantages of the ubiquitous learning environment, TC replied that: "The PDA will remind the students of the details of each learning task, and this will make them learn with less pressure." Furthermore, all three of the teachers mentioned the function for recording the learning process. For example, TA stated that: "With this innovative system, it is possible to track the learning behaviors of individual students. This would make them more focused while participating in the learning activity."

As for the "participation" perspective, the three teachers showed the same position on the ubiquitous learning environment. For instance, when asked about the benefits of the approach, TA used a quite positive perspective to express views regarding the "operational experiences" of the system. Similar standpoints could be found in the interview responses of TB and TC. TB responded that: "The ubiquitous learning system shows every operating procedure to assist the students in operating the equipment, which is quite different from using simulation systems on computers." This shows the value of learning from operational experiences. Consequently, it can be concluded that the u-learning environment has the potential to motivate the students to learn more willingly and to improve their learning effectiveness by providing operational learning experiences.

\section{Discussion and conclusions}

Mobile and wireless communication technologies have become popular among research groups. In ubiquitous learning, the students are situated in a real-world 
environment with support from the digital world. Owing to the novelty and pleasure of using mobile devices outside the classroom, such learning activities frequently receive promising feedback from the students (Hwang et al., 2009). Therefore, most researchers and school teachers regard such equipment as a convenient channel that enables students to access digital resources from the Internet. Nevertheless, the issue of developing new strategies or tools to improve the learning achievements of students in such learning environments has attracted relatively little attention.

In this paper, we presented a ubiquitous learning system for conducting scientific inquiry activities in an authentic learning environment. A learning guidance mechanism is proposed to help the students learn to employ scientific devices in a science park in order to find answers via operating the devices and interpreting the outcomes. The developed system has been applied to a learning activity of a science course in an elementary school. It should be noted that the learning activity is part of the existing science curriculum of the school, which complies with what has been emphasised by Zhang et al., (2010) that the use of mobile technologies to support learning should be treated as a part of schools' existing science curricula.

The experimental results show that the proposed approach is significantly more effective than the traditional approach in improving the learning achievements of individual students. In addition, from the questionnaire results, it is found that most of the students showed quite positive attitudes toward learning science with the new approach, in comparison with their previous experiences of the traditional approach; for example, $95 \%$ of the experimental group students indicated that "I became more willing to observe and investigate those science phenomena after participating in this ubiquitous learning activity," and 100\% of them became more willing to take the science course after participating in the learning activity.

From the teachers' feedback in the interviews, it is found that the effectiveness of this approach could be due to the provision of the instant guidance and feedback to individual students during their exploration and device-operating process. The students' experiences in this learning activity (i.e., learning via operating the devices) is different from those of the traditional approach in which the students are asked to complete their learning tasks based on a printed learning sheet after listening to the teachers' instructions. Such results conform to what educators have indicated; that is, with proper design, technologies can be used as knowledge construction tools that students learn with, not from (Kommers, Jonassen, \& Mayes, 1992; Jonassen, 1999). Therefore, this study has the rather positive implication that inquiry-based ubiquitous learning can be an effective approach to assisting students in using what they have learned in the class in actual fieldwork. A follow-up interview of the students who participated in the learning activity in the semester subsequent to the reported observations also showed that their attitudes toward learning science remained quite positive.

In addition, in the past few years, the rapid advancement and popularity of mobile and sensing technologies have further provide the opportunity to apply widely the learning approach presented in this study to more applications. For example, the popularity of the QR-code and smartphones (or e-books) offers an alternative to accomplish the approach with a much lower cost than using RFID and PDA, showing the increasing potential of the proposed approach. 
Although the provision of instant learning supports to individual students has achieved satisfactory results, the retention effect of the $\mathrm{u}$-learning approach needs to be further investigated. It is expected that in the future the notation of scaffolding originating from Vygotsky's (1978) zone of proximal development (ZPD) can be applied to such a learning activity. ZPD refers to the gap between individual learners' actual development level (i.e., knowledge and skills that the learners can obtain without any support) and the potential development level (i.e., the knowledge and skill levels that the learners can achieve with proper supports). Scaffolding is such an instructional support that helps learners narrow the gap, that is, it moves them from their actual development level to their potential development level. In other words, scaffolding is the instructional support that helps individual learners complete learning tasks beyond their ability ( $\mathrm{Wu} \&$ Pedersen, 2011). In the past decade, researchers have shown the effectiveness of scaffolding in helping students improve their learning performance. For example, Li and Lim (2008) examined the different dimensions of scaffolding for online historical inquiry and found that well-designed scaffolds could benefit students in each step of the inquiry activity. Zydney (2010) further investigated the effectiveness of multiple scaffolding tools in helping students understand a complex problem, and found that scaffolding tools had varying effects on students' problem understanding, and a significant interaction was found between the different scaffolding tools used.

Among various scaffolding strategies, researchers have indicated that questioning strategies had a significant effect on students' performance in a technology-enhanced environment (Demetriadis et al., 2008; Ge \& Land, 2003). Therefore, in the future, we plan to design a large-scale and long-term inquiry-based scaffolding approach to assist students in improving their learning achievements in the science park; moreover, the retention effects will be investigated after the scaffolding is faded out.

\section{Acknowledgments}

This study is supported in part by the National Science Council, Taiwan, under contract numbers NSC 99-2511-S-031-002-MY2 and NSC 100-2631-S-011-003, and by NSERC, iCORE, Xerox, and research related funding by Mr. A. Markin.

\section{References}

Anderson, D., Lucas, K. B., Ginns, I. S. \& Dierking, L. D. (2000). Development of knowledge about electricity and magnetism during a visit to a science museum and related post-visit activities. Science Education, 84(5), 658-679. http: / / dx.doi.org/10.1002/1098237X(200009)84:5<658::AID-SCE6>3.0.CO;2-A

Atkins, L. J., Velez, L., Goudy, D. \& Dunbar, K. N. (2009). The unintended effects of interactive objects and labels in the science museum. Science Education, 93(1), 161-184. http: / / dx.doi.org/10.1002/ sce.20291

Burleson, W. (2005). Developing creativity, motivation, and self-actualization with learning systems. International Journal of Human-Computer Studies, 63(4/5), 436-451. http: / / dx.doi.org/10.1016/j.ijhcs.2005.04.007

Chen, C. H., Hwang, G. J., Yang, T. C., Chen, S. H. \& Huang, S. Y. (2009). Analysis of a ubiquitous performance support system for teachers. Innovations in Education and Teaching International, 46(4), 421-433. http: / / dx.doi.org/10.1080/14703290903301727 
Chen, S. (2010). The view of scientific inquiry conveyed by simulation-based virtual laboratories. Computers $\mathcal{E}$ Education, 55(3), 1123-1130. http:/ / dx.doi.org/10.1016/j.compedu.2010.05.009

Chen, Y. S., Kao, T. C. \& Sheu, J. P. (2003). A mobile learning system for scaffolding bird watching learning. Journal of Computer Assisted Learning, 19(3), 347-359. http: / / dx.doi.org/10.1046/j.0266-4909.2003.00036.x

Chu, H. C., Hwang, G. J. \& Tsai, C.C. (2010). A knowledge engineering approach to developing mindtools for context-aware ubiquitous learning. Computers $\mathcal{E}$ Education, 54(1), 289-297. http: / / dx.doi.org/10.1016/j.compedu.2009.08.023

Dalgarno, B., Bishop, A. G., Adlong, W. \& Bedgood, D. R. (2009). Effectiveness of a virtual laboratory as a preparatory resource for distance education chemistry students. Computers $\mathcal{E}$ Education, 53(3), 853-865. http: / / dx.doi.org/10.1016/j.compedu.2009.05.005

Demetriadis, S. N., Papadopoulos, P. M., Stamelos, I. G. \& Fischer, F. (2008). The effect of scaffolding students' context-generating cognitive activity in technology-enhanced casebased learning. Computers $\mathcal{E}$ Education, 51(2), 939-954. http: / / dx.doi.org/10.1016/j.compedu.2007.09.012

El-Bishouty, M. M., Ogata, H. \& Yano, Y. (2007). PERKAM: Personalized knowledge awareness map for computer supported ubiquitous learning. Educational Technology E Society, 10(3), 122-134. http: / / www.ifets.info/journals/10_3/9.pdf

Ge, X. \& Land, S. M. (2003). Scaffolding students' problem-solving processes in an ill-structured task using question prompts and peer interactions. Educational Technology Research and Development, 51(1), 21-38. http:/ / dx.doi.org/10.1007/BF02504515

Gerber, B. L., Cavallo, A. M. L. \& Marek, E. A. (2001). Relationships among informal learning environments, teaching procedures and scientific reasoning ability. International Journal of Science Education, 23(5), 535-549. http: / / dx.doi.org/10.1080/ 095006901750162892

Herrington, J. \& Oliver, R. (2000). An instructional design framework for authentic learning environments. Educational Technology Research \& Development, 48(3), 23-48. http: / / ro.uow.edu.au / cgi/ viewcontent.cgi?article=1031\&context=edupapers

Holzinger, A., Kickmeier-Rust, M. D., Wassertheurer, S. \& Hessinger, M. (2009). Learning performance with interactive simulations in medical education: Lessons learned from results of learning complex physiological models with the HAEMOdynamics SIMulator. Computers $\mathcal{E}$ Education, 52(2), 292-301. http: / / dx.doi.org/10.1016/j.compedu.2008.08.008

Hung, P. H., Lin, Y. F. \& Hwang, G. J. (2010). Formative assessment design for PDA integrated ecology observation. Educational Technology E Society, 13(3), 33-42. http://www.ifets.info/journals/13_3/5.pdf

Hwang, G. J. \& Chang, H. F. (2011). A formative assessment-based mobile learning approach to improving the learning attitudes and achievements of students. Computers $\mathcal{E}$ Education, 56(4), 1023-1031. http: / / dx.doi.org/10.1016/j.compedu.2010.12.002

Hwang, G. J., Chu, H. C., Lin, Y.S. \& Tsai, C. C. (2011). A knowledge acquisition approach to developing Mindtools for organizing and sharing differentiating knowledge in a ubiquitous learning environment. Computers $\mathcal{E}$ Education, 57(1), 1368-1377. http: / / dx.doi.org/10.1016/j.compedu.2010.12.013

Hwang, G. J., Wu, C. H., Tseng, Judy C. R. \& Huang, I. W. (2011). Development of a ubiquitous learning platform based on a real-time help-seeking mechanism. British Journal of Educational Technology, 42(6), 992-1002. http:/ / dx.doi.org/10.1111/j.1467-8535.2010.01123.x 
Hwang, G. J., Shi, Y. R. \& Chu, H. C. (2011). A concept map approach to developing collaborative Mindtools for context-aware ubiquitous learning. British Journal of Educational Technology, 42(5), 778-789. http:/ / dx.doi.org/10.1111/j.1467-8535.2010.01102.x

Hwang, G. J., Tsai, C. C. \& Yang, S. J. H. (2008). Criteria, strategies and research issues of context-aware ubiquitous learning. Journal of Educational Technology E Society, 11(2), 81-91. http://www.ifets.info/journals/11_2/8.pdf

Hwang, G. J., Yang, T. C., Tsai, C. C. \& Yang, S. J. H. (2009). A context-aware ubiquitous learning environment for conducting complex science procedures. Computers $\mathcal{E}$ Education, 53(2), 402413. http:/ / dx.doi.org/10.1016/j.compedu.2009.02.016

Johnson, E. P., Perry, J. \& Shamir, H. (2010). Variability in reading ability gains as a function of computer-assisted instruction method of presentation. Computers $\mathcal{E}$ Education, 55(1), 209-217. http:/ / dx.doi.org/10.1016/j.compedu.2010.01.006

Jonassen, D. H. (1999). Computers as mindtools for schools: Engaging critical thinking. Englewood Cliffs, NJ: Prentice-Hall.

Ketelhut, D. J. \& Schifter, C. C. (2011). Teachers and game-based learning: Improving understanding of how to increase efficacy of adoption. Computers $\mathcal{E}$ Education, 56(2), 539-546. http: / / dx.doi.org/10.1016/j.compedu.2010.10.002

Kommers, P., Jonassen, D. H. \& Mayes, T. (Eds.) (1992). Cognitive tools for learning. Heidelberg, FRG: Springer.

Kong, S. C., Yeung, Y. Y. \& Wu, X. Q. (2009). An experience of teaching for learning by observation: Remote-controlled experiments on electrical circuits. Computers $\mathcal{E}$ Education, 52(3), 702-717. http: / / dx.doi.org/10.1016/j.compedu.2008.11.011

Leng, B. A. de., Dolmans, D. H. J. M., Jöbsis, R., Muijtjens, A. M. M. \& van der Vleuten, C. P. M. (2009). Exploration of an e-learning model to foster critical thinking on basic science concepts during work placements. Computers \& Education, 53(1), 1-13. http:// dx.doi.org/10.1016/j.compedu.2008.12.012

Li, D. D. \& Lim, C. P. (2008). Scaffolding online historical inquiry tasks: A case study of two secondary school classrooms. Computers E Education, 50(4), 1394-1410. http:/ / dx.doi.org/10.1016/j.compedu.2006.12.013

Li, L., Liu, X. \& Steckelberg, A. L. (2010). Assessor or assessee: How student learning improves by giving and receiving peer feedback. British Journal of Educational Technology, 41(3), 525-536. http: / / dx.doi.org/10.1111/j.1467-8535.2009.00968.x

Manlove, S., Lazonder, A. W. \& de Jong, T. (2006). Regulative support for collaborative scientific inquiry learning. Journal of Computer Assisted Learning, 22(2), 87-98. http: / / dx.doi.org/10.1111/j.1365-2729.2006.00162.x

Marx, R. W., Blumenfeld, P. C., Krajcik, J. S., Fishman, B., Soloway, E., Geier, R. \& Tal, R. T. (2004). Inquiry-based science in the middle grades: assessment of learning in urban systemic reform. Journal of Research in Science Teaching, 41(10), 1063-1080. http: / / dx.doi.org/10.1002/ tea.20039

National Research Council (2000). Inquiry and the national science education standards: A guide for teaching and learning. Washington, DC: National Academy Press. http: / / www.nap.edu / openbook.php?isbn=0309064767 
Ogata, H. \& Yano, Y. (2004). Context-aware support for computer-supported ubiquitous learning. Proceedings, 2nd IEEE International Workshop on Wireless and Mobile Technologies in Education. JhongLi, Taiwan. http:/ / ieeexplore.ieee.org/xpl/login.jsp?tp=\&arnumber=1281330

Paige, J. B. \& Daley, B. J. (2009). Situated cognition: A learning framework to support and guide high-fidelity simulation. Clinical Simulation in Nursing, 5(3), e97-e103. http: / / dx.doi.org/10.1016/j.ecns.2009.03.120

Panjaburee, P., Hwang, G. J., Triampo, W. \& Shih, B. Y. (2010). A multi-expert approach for developing testing and diagnostic systems based on the concept-effect model. Computers $\mathcal{E}$ Education, 55(2), 527-540. http:/ / dx.doi.org/10.1016/j.compedu.2010.02.015

Peng, H., Chou, C. \& Chang, C.-Y. (2008). From virtual environments to physical environments: Exploring interactivity in ubiquitous-learning systems. Educational Technology E Society, 11(2), 54-66. http:/ / www.ifets.info/journals /11_2/6.pdf

Phillips, M., Finkelstein, D. \& Wever-Frerichs, S. (2007). School site to museum floor: How informal science institutions work with schools. International Journal of Science Education, 29(12), 1489-1507. http:/ / dx.doi.org/10.1080/09500690701494084

Reeves, T. C. (1993). Psuedoscience in computer-based instruction: The case of learner control research. Journal of Computer-Based Instruction, 20(2), 39-46.

Rogers, Y., Price, S., Randell, C., Fraser, D. S., Weal, M. \& Fitzpatrick, G. (2005). Ubi-learning integrating indoor and outdoor learning experiences. Communications of the ACM, 48(1), 5559. http: / / dx.doi.org/10.1145/1039539.1039570

Schiaffino, S., Garcia, P. \& Amandi, A. (2008). eTeacher: Providing personalized assistance to elearning students. Computers \& Education, 51(4), 1744-1754. http: / / dx.doi.org/10.1016/j.compedu.2008.05.008

Sharples, M., Taylor, J. \& Vavoula, G. (2007). A theory of learning for the mobile age. In R. Andrews \& C. Haythornthwaite (Eds.), The Sage handbook of elearning research. London: Sage, pp. 221-47.

Tomkins, S. P. \& Tunnicliffe, S. D. (2001). Looking for ideas: Observation, interpretation and hypothesis-making by 12-year-old pupils undertaking science investigations. International Journal of Science Education, 23(8), 791-813. http:/ / dx.doi.org/10.1080/09500690010016049

Tseng, S. C. \& Tsai, C. C. (2007). On-line peer assessment and the role of the peer feedback: A study of high school computer course. Computers and Education, 49(4), 1161-1174. Http: / / dx.doi.org/10.1016/j.compedu.2006.01.007

Vygotsky, L. S. (1978). Mind in society: The development of higher psychological processes. Cambridge, MA: Harvard University Press.

Williams van Rooij, S. (2009). Scaffolding project-based learning with the project management body of knowledge (PMBOK). Computers $\mathcal{E}$ Education, 52(1), 210-219.

http: / / dx.doi.org/10.1016/j.compedu.2008.07.012

Wu, H. L. \& Pedersen, S. (2011). Integrating computer- and teacher-based scaffolds in science inquiry. Computers $\mathcal{E}$ Education, 57(4), 2352-2363.

http:// dx.doi.org/10.1016/j.compedu.2011.05.011

Zhang, B. H., Looi, C. K., Seow, P., Chia, G., Wong, L. H., Chen, W., So, H. J., Soloway, E. \& Norris, C. (2010). Deconstructing and reconstructing: Transforming primary science learning via a mobilized curriculum. Computers \& Education, 55(4), 1504-1523. http: / / dx.doi.org/10.1016/j.compedu.2010.06.016 
Zydney, J. M. (2010). The effect of multiple scaffolding tools on students' understanding, consideration of different perspectives, and misconceptions of a complex problem. Computers $\mathcal{E}$ Education, 54(2), 360-370. http:/ / dx.doi.org/10.1016/j.compedu.2009.08.017

Authors: Gwo-Jen Hwang, Chair Professor

Graduate Institute of Digital Learning and Education

National Taiwan University of Science and Technology

43, Sec.4, Keelung Rd., Taipei, 106, Taiwan

Email: gjhwang.academic@gmail.com

Chin-Chung Tsai, Chair Professor

Graduate Institute of Digital Learning and Education

National Taiwan University of Science and Technology, Taiwan

43, Sec.4, Keelung Rd., Taipei, 106, Taiwan

Email: cctsai@mail.ntust.edu.tw

Hui-Chun Chu, Assistant Professor

Department of Computer Science and Information Management

Soochow University, 56, Sec. 1, Kui-Yang St., Taipei 100, Taiwan

E-mail: carolhcchu@gmail.com

Kinshuk, Professor

School of Computing and Information Systems

Athabasca University, 1 University Drive, Athabasca, AB T9S 3A3, Canada

Email: kinshuk@ieee.org

Chieh-Yuan Chen, Masters degree student

Department of Information and Learning Technology

National University of Tainan, 33, Sec. 2, Shu-Lin St., Tainan 700, Taiwan

Email: yugin2004@gmail.com

Please cite as: Hwang, G. J., Tsai, C. C., Chu, H. C., Kinshuk \& Chen, C. Y. (2012). A context-aware ubiquitous learning approach to conducting scientific inquiry activities in a science park. Australasian Journal of Educational Technology, 28(5), 931-947.

http:/ / www.ascilite.org.au/ajet/ajet28/hwang.html 